\title{
High-Flow Nasal Cannula in Critically Ill Subjects With or at Risk for Respiratory Failure: A Systematic Review and Meta-Analysis
}

\author{
Wagner Luis Nedel MD MSc, Caroline Deutschendorf MD MSc, and \\ Edison Moraes Rodrigues Filho MD PhD
}

\author{
Introduction \\ Methods \\ Results \\ High-Flow Nasal Cannula and Invasive Mechanical Ventilation \\ High-Flow Nasal Cannula and Mortality \\ High-Flow Nasal Cannula and Oxygenation Improvement \\ Discussion \\ Conclusion
}

\begin{abstract}
High-flow nasal cannula (HFNC) oxygen delivery has been gaining attention as an alternative means of respiratory support for critically ill patients, with recent studies suggesting equivalent outcomes when compared with other forms of oxygen therapy delivery. The main objective of this review was to extract current data about the efficacy of HFNC in critically ill subjects with or at risk for respiratory failure. We performed a systematic review of publications (from database inception to October 2015) that evaluated HFNC in critically ill subjects with or at risk for acute respiratory failure and performed a meta-analysis comparing HFNC with noninvasive ventilation (NIV) and with standard oxygen therapy regarding major outcomes: incidence of invasive mechanical ventilation and ICU mortality. A total of 9 studies were included. HFNC was not associated with a reduction in the incidence of invasive mechanical ventilation compared with NIV (odds ratio [OR] 0.83, 95\% CI 0.57-1.20, $P=.31$ ) or standard oxygen therapy (OR 0.49, 95\% CI 0.22-1.08, $P=.17$ ). Additionally, HFNC use did not reduce ICU mortality compared with NIV (OR $0.72,95 \%$ CI $0.23-2.21, P=.56$ ) or with standard oxygen therapy (OR 0.69, 95\% CI 0.33-1.42, $P=.29$ ). There was a trend toward better oxygenation compared with conventional oxygen therapy but a worse gas exchange compared with NIV. At this moment, HFNC therapy seems not to be superior to conventional oxygen therapy or NIV in terms of invasive mechanical ventilation rate or ICU mortality in critical illness, but new studies are needed to determine whether HFNC is associated with any difference in major outcomes when compared with other techniques. Key words: high-flow nasal cannula; noninvasive ventilation; oxygen therapy. [Respir Care 2017;62(1):123-132.

(C) 2017 Daedalus Enterprises]
\end{abstract}

\section{Introduction}

Oxygen therapy is one of the most prescribed treatments in medicine, especially in critical care patients. It is an

Dr Nedel is affiliated with the ICU, Hospital Nossa Senhora da Conceição and the ICU, Hospital de Clinicas de Porto Alegre, Porto Alegre, Brazil. Dr Deutschendorf is affiliated with the Infection Control Unit, Hospital de Clínicas de Porto Alegre, Porto Alegre, Brazil. Dr Moraes adjunctive therapy in respiratory support, the purpose of which is to maintain adequate ventilation and oxygenation, thereby providing adequate alveolar gas exchange. Highflow nasal cannula (HFNC) oxygen delivery has been gaining attention as an alternative means of oxygen therapy for

Rodrigues Filho is affiliated with the ICU, Hospital de Clinicas de Porto Alegre, Porto Alegre, Brazil.

The authors have disclosed no conflicts of interest. 


\section{HFNC in CRitically Ill Subjects With or at Risk for Respiratory Failure}

critically ill patients. The apparatus comprises an air-oxygen blender, an active heated humidifier, a single heated circuit, and a nasal cannula. At the air-oxygen blender, $\mathrm{F}_{\mathrm{IO}_{2}}$ is set up to 1.0 at a maximum flow of $60 \mathrm{~L} / \mathrm{min}$ via a nasal cannula. The gas is heated and humidified with the active humidifier and delivered through the heated circuit, which increases patient tolerance ${ }^{1}$ without the potential side effects of an increased dead space provided by noninvasive ventilation (NIV). HFNC offers several physiological advantages that might encourage its use, including, but not limited to, improvements in oxygenation, the generation of a flow-dependent PEEP, reduction of nasopharyngeal resistance and pharyngeal dead space washout, and an increase in end-expiratory lung volume..$^{2,3}$

Most of the available data regarding this technique have been published in the neonatal field. ${ }^{4,5}$ Currently, HFNC use is increasing in a variety of critically ill adult patients with diverse underlying conditions, including acute respiratory failure, ${ }^{6-8}$ during bronchoscopy, ${ }^{9}$ or to prevent severe desaturation during intubation of patients with mildto-moderate hypoxemia, despite the lack of reliable, large, controlled clinical trials published. ${ }^{10-12}$ Some authors even define the postextubation scenario as "at risk for respiratory failure," despite the same clinical management as compared with true "respiratory failure." 11

The objective of this study was to extract current data about the actual efficacy of HFNC in critically ill subjects with or at risk for respiratory failure, and, through a metaanalysis, specify the effects of this support in terms of relevant outcomes (mortality, need for invasive mechanical ventilation, improvement in gas exchange).

\section{Methods}

Our study was performed according to the recommendations of the Preferred Reporting Items for Systematic Reviews and Meta-Analysis (PRISMA) statement. ${ }^{13}$ The study protocol was published in the PROSPERO database (www.crd.york.ac.uk/PROSPERO) with number CRD42015025912. We performed a systematic search of MEDLINE, the Cochrane Database, and EMBASE (from the inception of each database to June 2015) to identify full-text publications in English, Spanish, French, and Portuguese that evaluated the use of HFNC treatment in clinical-surgical critically ill subjects with acute hypoxemic respiratory failure or at risk for this complication, compared with standard oxygen therapy or NIV. The primary

Correspondence: Wagner L Nedel MD MSc, Avenida João XXIII, 525, 801E, Porto Alegre/RS, Brazil 91060100. E-mail: wagnernedel@uol.com.br.

DOI: $10.4187 /$ respcare. 04831 outcome was the intubation rate in different groups, whereas the secondary outcomes were oxygenation improvement (defined as $\mathrm{P}_{\mathrm{aO}_{2}} / \mathrm{F}_{\mathrm{IO}_{2}}$ ), mechanical ventilation time, and ICU mortality. The following major medical subject headings terms were included: ("respiratory insufficiency" OR "respiratory distress syndrome, adult" OR "shock lung" OR "acute lung injury" OR "lung diseases, obstructive" OR "pneumonia") AND (high-flow AND ("nose" OR "nasal") AND ("catheters" OR "cannula")) OR (high-flow AND "oxygen") OR optiflow OR "oxygen inhalation therapy." The references of review articles were also reviewed to identify any other potentially eligible articles.

The review was limited to adult subjects, and only original peer-reviewed randomized controlled trials were selected. Exclusion criteria were observational studies and quasi-experimental trials and patients with a donot-intubate order in the emergency room or in the general ward. Two authors (WLN and EMRF) independently reviewed the abstracts of all citations from the search and the full articles for inclusion. Then selected articles were compared by a third author (CD) who resolved any disagreements. The following data were extracted: study location, enrollment period, sample size, inclusion and exclusion criteria, baseline characteristics, details of intervention and comparator groups, and clinical outcomes. To ascertain the validity and the risk of bias of the eligible randomized studies, 2 reviewers working independently used the Cochrane Collaboration's tool for assessing the risk of bias (version 5.1.0; http://handbook.cochrane.org).

The statistical analysis was performed using the MetaView statistical program within Review Manager software (RevMan 5.3.4, the Nordic Cochrane Center, Cochrane Collaboration, Copenhagen, Denmark) using the Mantel-Haenszel random effects model. Statistical heterogeneity across trials was assessed using the Cochrane chisquare test and the Higgins inconsistency test. We analyzed the probability of publication bias using funnel plots and considered plot asymmetry to be suggestive of reporting bias.

\section{Results}

The initial search identified 5,560 studies in PubMed, 5,610 in EMBASE, and 1,223 in Cochrane; after the removal of duplicates, 6,806 articles were reviewed. After review of the abstracts, 49 studies were retrieved and reviewed in detail. Finally, after full-text review, we excluded 42 records, and 9 articles met the inclusion criteria and were selected by both reviewers (Fig. 1). The main characteristics of the included studies are summarized in Table 1.

Three studies evaluated postextubation subjects ${ }^{14,17}$ : one in obese post-cardiac surgery subjects, ${ }^{18}$ one in sub- 


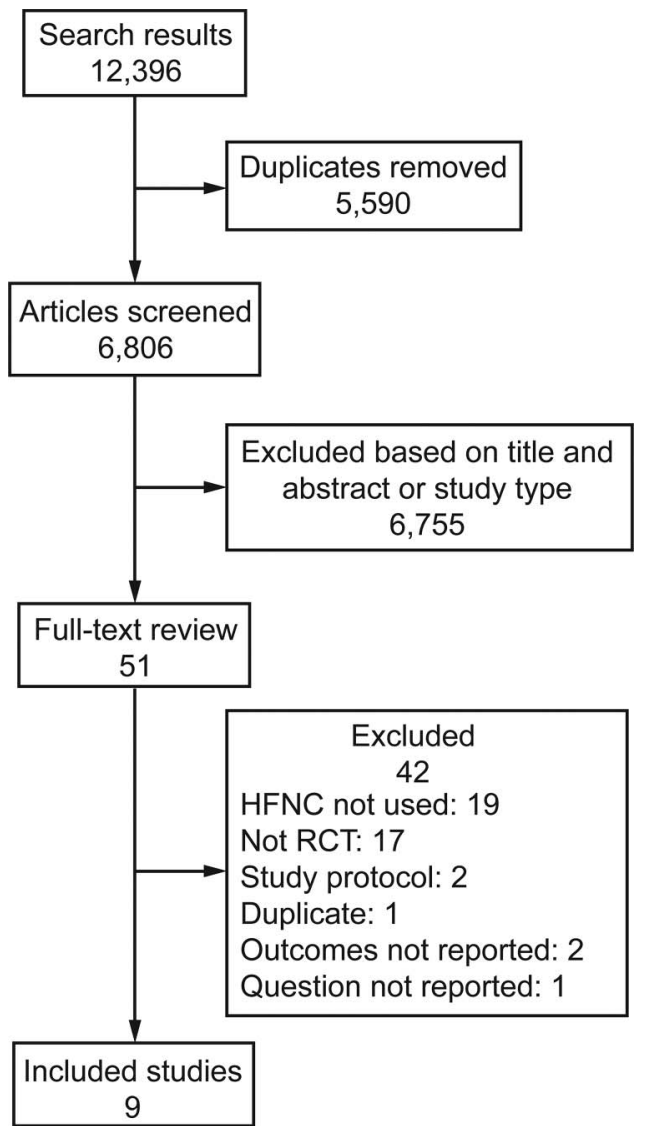

Fig. 1. Flow chart. HFNC = high-flow nasal cannula, RCT = randomized controlled trial.

jects with hypoxemic respiratory failure undergoing diagnostic fibrobronchoscopy, ${ }^{9}$ and 3 in medical subjects with acute respiratory failure, ${ }^{12,15,16}$ including one in immunosuppressed subjects. ${ }^{19}$ One randomized controlled trial was performed in a crossover fashion, ${ }^{14} 5$ were single-center, ${ }^{14,15,16,18}$ and 4 were multi-center. ${ }^{11,12,17,19}$ The main comparator was conventional oxygen therapy; 3 studies compared with air-entrainment mask, $16,17,192$ studies compared with standard oxygen therapy, ${ }^{12,18}$ and 2 studies compared with high-flow face mask. ${ }^{14,15}$ Two studies compared with NIV,9,16 whereas one compared with NIV and conventional oxygen therapy. ${ }^{12}$

Overall, subjects had well-balanced baseline characteristics in each group (with the exception of the study by Simon et al, ${ }^{9}$ in which more subjects with hematological disorders and more subjects with hospital-acquired pneumonia were allocated in the HFNC group). The Simplified Acute Physiology Score II was the main disease severity score employed by the studies, ${ }^{9,11,12,16,17,19}$ with scores varying between $25^{12}$ and $46 .{ }^{9}$ The breathing frequency was also variable in a range between $18^{15}$ and 33 breaths $/ \mathrm{min}^{12}$; similarly, there was heterogeneity in the reported $\mathrm{P}_{\mathrm{aO}_{2}} / \mathrm{F}_{\mathrm{IO}_{2}}$ (from 128 in Lemiale et al ${ }^{19}$ to 241 in
Maggiore et $\left.\mathrm{al}^{17}\right)$. There were no significant differences between studies about baseline arterial $\mathrm{pH}$ (from 7.37 to 7.46) or in baseline $\mathrm{P}_{\mathrm{CO}_{2}}$ (from 35 to 42). The length of ICU stay varied from $1.5 \mathrm{~d}$ in Corley et al ${ }^{18}$ to $11 \mathrm{~d}$ in Maggiore et $\mathrm{al}^{17}$ Results of the Cochrane Risk of Bias Tool of the included studies are presented in Table 2. Overall, there was a preponderance of good methodological randomized controlled trials, with the great majority of trials reporting sequence generation, allocation concealment, and intention-to-treat analysis. None of the studies, however, presented blinding of outcome assessment and, due to the nature of the intervention, none of them performed blinding of participants and personnel.

\section{HFNC and Invasive Mechanical Ventilation}

HFNC demonstrated outcomes similar to NIV with respect to the need for invasive mechanical ventilation in a meta-analysis of 3 trials (OR 0.83 , 95\% CI $0.57-1.20$, $P=.31, \mathrm{I}^{2}=22 \%$ ) with a low heterogeneity among studies (Fig. 2). Similar outcomes to conventional oxygen therapy were also observed (OR $0.49,95 \%$ CI $0.22-1.08$, $\left.P=.17, \mathrm{I}^{2}=37 \%\right)$ in a moderate heterogeneity metaanalysis of 5 trials (Fig. 3) of hypoxemic respiratory failure in medical (3 trials, one in immunosuppressed subjects), surgical (one study), and post-procedure (one study) subjects.

\section{HFNC and Mortality}

Two studies compared HFNC and NIV mortality in hypoxemic respiratory failure, and there was no difference between groups in their meta-analysis (OR 0.72, 95\% CI $0.23-2.21, P=.56, \mathrm{I}^{2}=83 \%$ ) (Fig. 4); that meta-analysis also showed no difference between groups in the comparison of HFNC and standard oxygen therapy (OR $0.69,95 \%$ CI $0.33-1.42, P=.29, \mathrm{I}^{2}=11 \%$ ) (Fig. 5).

\section{HFNC and Oxygenation Improvement}

Overall, we identified 6 studies comparing oxygenation pre- and post-HFNC therapy, 4 with conventional oxygen therapy and 2 with NIV. We opted not to subject these data to meta-analysis because of the substantial heterogeneity among the studies in terms of interventions, measured outcomes, and different time intervals. Compared with high-flow face mask, there was no difference in post-intervention $\mathrm{P}_{\mathrm{aO}_{2}}$ between groups ${ }^{14}$; however, better $\mathrm{P}_{\mathrm{aO}} / \mathrm{F}_{\mathrm{IO}_{2}}$ ratios were observed at $4 \mathrm{~h}$ postintervention. In another study, the regression analysis found that HFNC was also associated with fewer desaturation episodes. ${ }^{20}$ In 2 studies, HFNC was inferior to NIV with regard to $\mathrm{P}_{a O_{2}} 30$ min post-intervention 


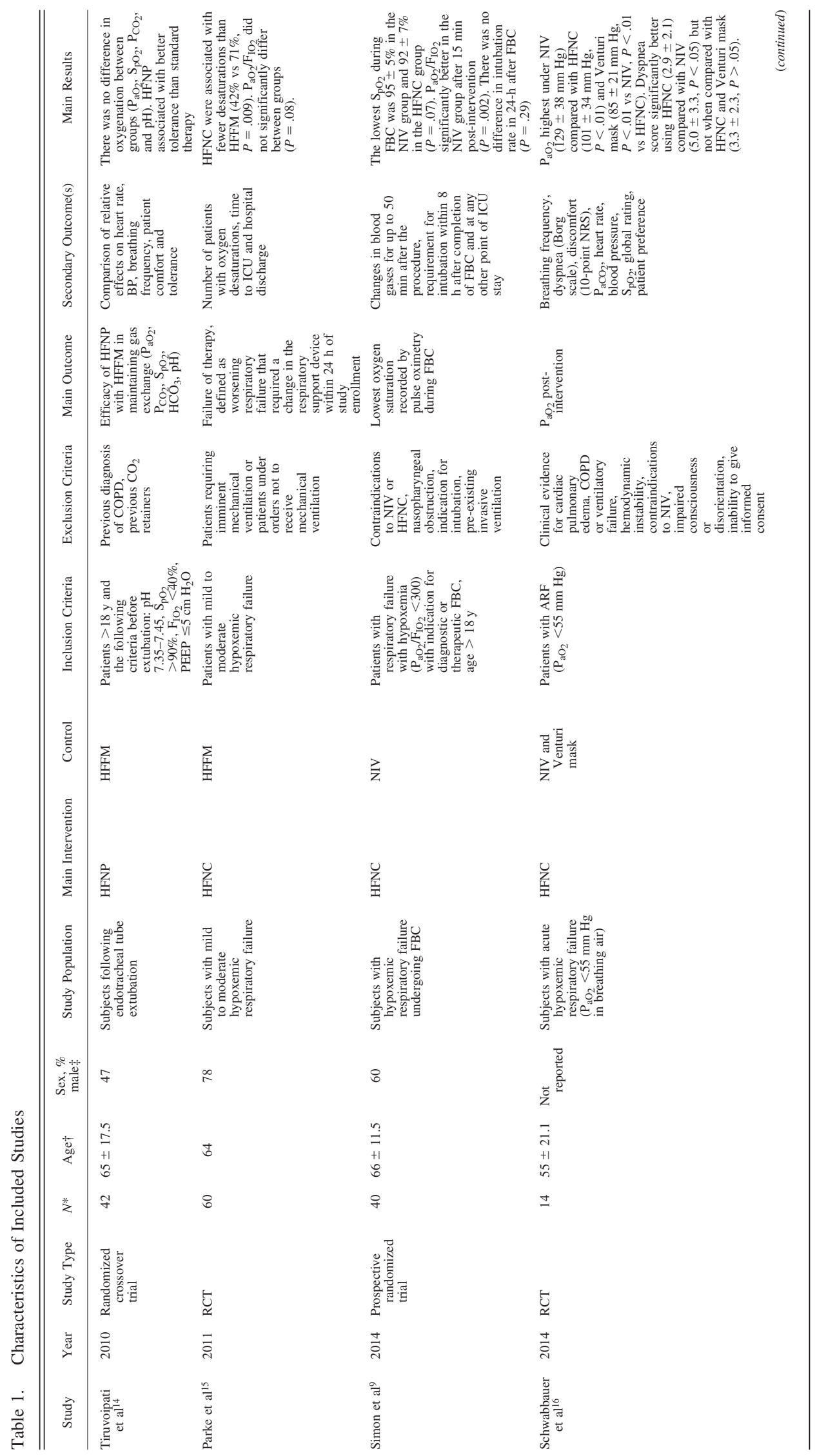




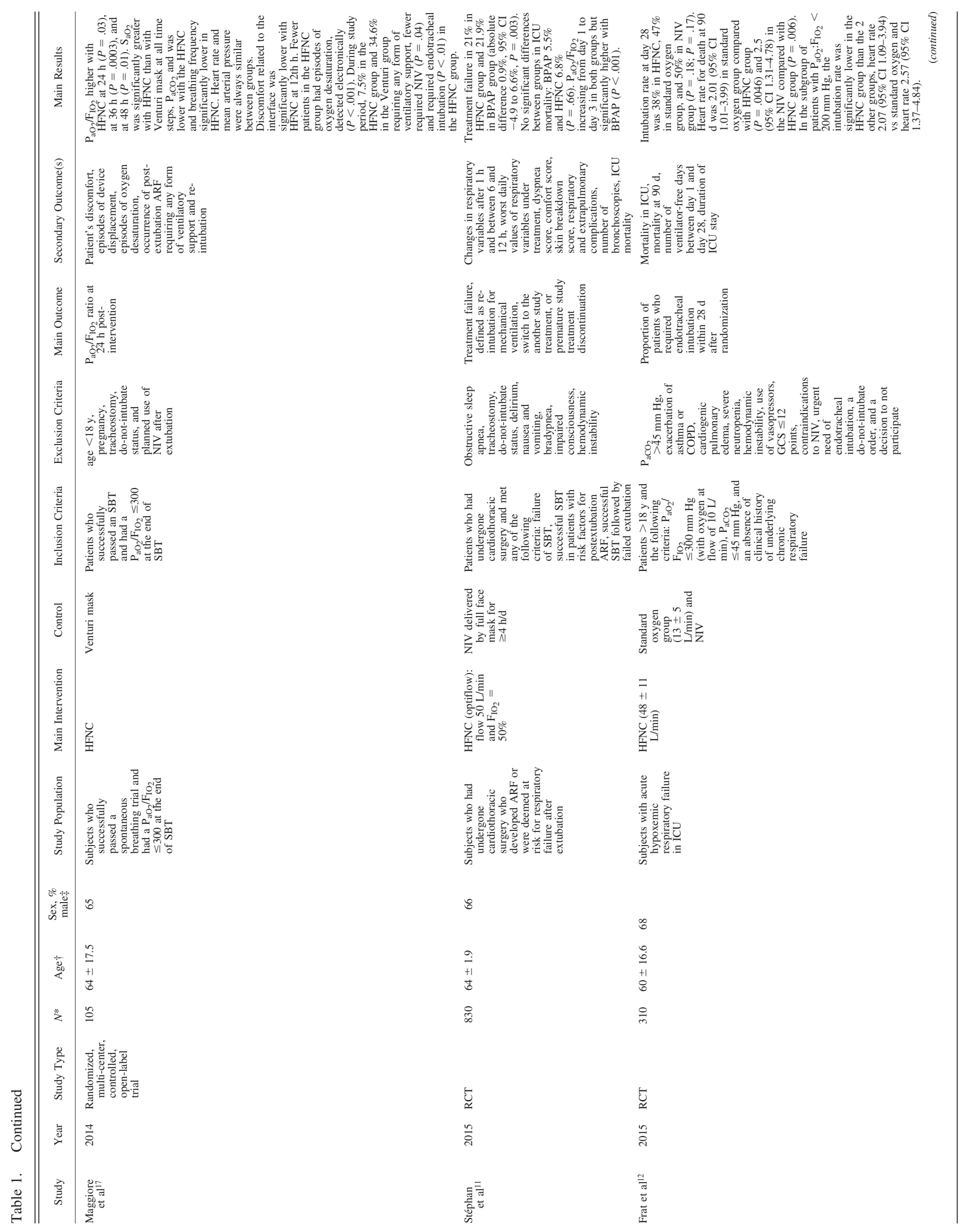




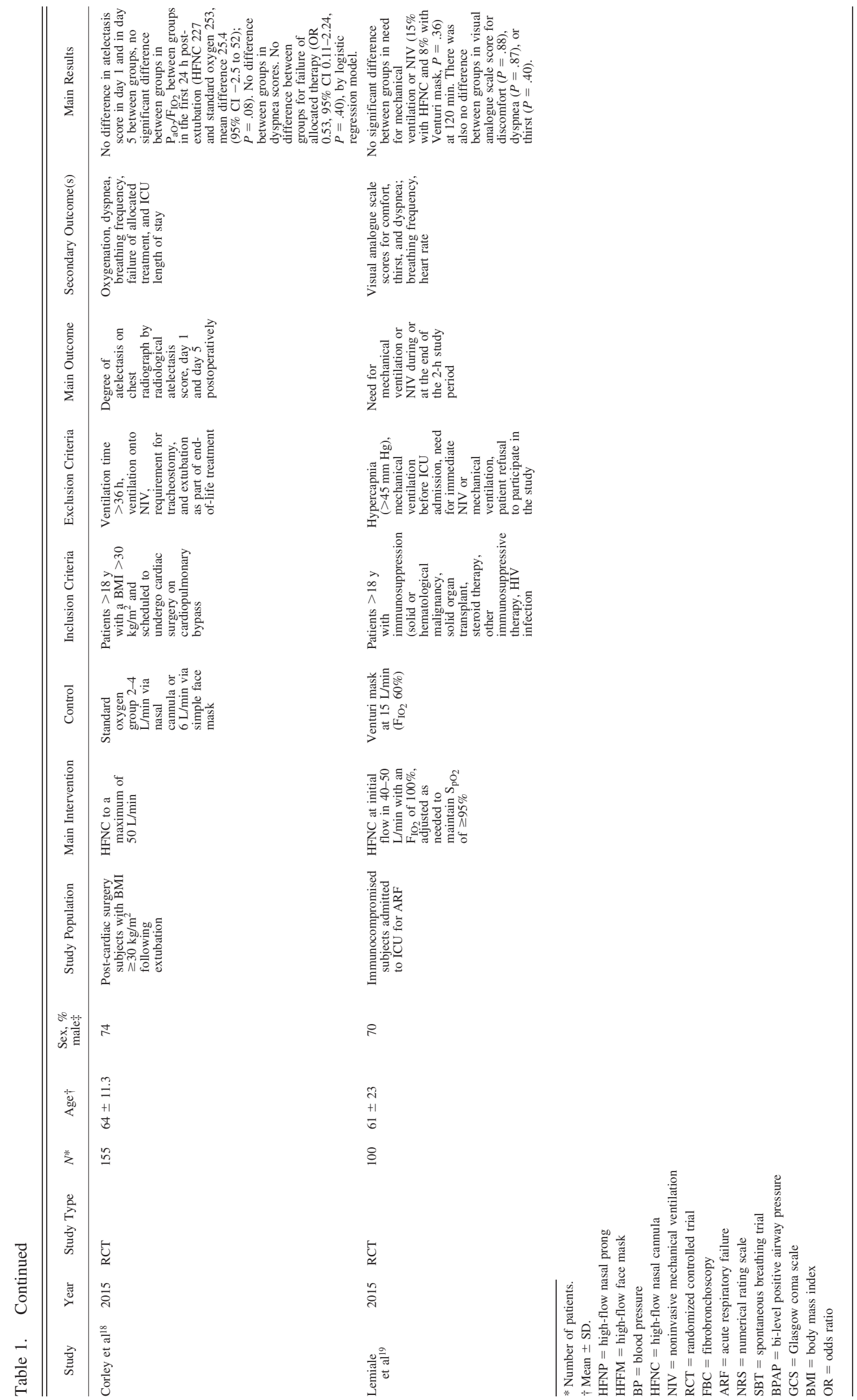




\section{HFNC in CRitically Ill Subjects With or at Risk for Respiratory Failure}

Table 2. Cochrane Risk of Bias Tool

\begin{tabular}{|c|c|c|c|c|c|c|c|}
\hline Study & $\begin{array}{l}\text { Sequence } \\
\text { Generation }\end{array}$ & $\begin{array}{c}\text { Allocation } \\
\text { Concealment }\end{array}$ & $\begin{array}{l}\text { Blinding of } \\
\text { Participants and } \\
\text { Personnel }\end{array}$ & $\begin{array}{l}\text { Blinding of } \\
\text { Outcome } \\
\text { Assessment }\end{array}$ & $\begin{array}{l}\text { Incomplete } \\
\text { Outcome Data }\end{array}$ & $\begin{array}{l}\text { Selective } \\
\text { Reporting }\end{array}$ & $\begin{array}{c}\text { Intention-to-Treat } \\
\text { Analysis }\end{array}$ \\
\hline Tiruvoipati et al $(2010)^{14}$ & Uncertain & Yes & No & No & Uncertain & Yes & No \\
\hline Parke et al $(2011)^{15}$ & Yes & Yes & Uncertain & Uncertain & Uncertan & Yes & Yes \\
\hline Simon et al $(2014)^{9}$ & Yes & Yes & No & No & Uncertain & Yes & No \\
\hline Schwabbauer et al (2014) & No & No & No & No & Uncertain & No & Uncertain \\
\hline Maggiore et al $(2014)^{17}$ & Yes & Yes & No & No & Yes & Yes & Yes \\
\hline Stéphan et al $(2015)^{11}$ & Yes & Yes & No & No & Uncertain & Yes & Yes \\
\hline Frat et al $(2015)^{12}$ & Yes & Yes & No & No & Yes & Yes & Yes \\
\hline Corley et al $(2015)^{18}$ & Yes & Yes & No & No & No & Yes & Yes \\
\hline Lemiale et al $(2015)^{19}$ & Yes & Yes & No & No & No & Yes & Yes \\
\hline
\end{tabular}

\begin{tabular}{|c|c|c|c|c|c|c|c|}
\hline \multirow[b]{2}{*}{ Study or Subgroup } & \multicolumn{2}{|c|}{ HFNC } & \multicolumn{2}{|c|}{ NIV } & \multicolumn{2}{|r|}{ Odds Ratio } & \multirow{2}{*}{$\begin{array}{c}\text { Odds Ratio } \\
\mathrm{M}-\mathrm{H}, \text { Random, } 95 \% \mathrm{Cl}\end{array}$} \\
\hline & Events & Total & Events & Total & Weight & $\mathrm{M}-\mathrm{H}$, Random, $95 \% \mathrm{Cl}$ & \\
\hline Frat et al ${ }^{12}$ & 40 & 106 & 55 & 110 & $34.7 \%$ & $0.61(0.35-1.04)$ & -2 \\
\hline Simon et $\mathrm{al}^{9}$ & 1 & 20 & 0 & 20 & $1.3 \%$ & $3.15(0.12-82.16)$ & \\
\hline Stéphan et $\mathrm{al}^{111}$ & 87 & 414 & 91 & 416 & $64.0 \%$ & $0.95(0.68-1.32)$ & \\
\hline Total $(95 \% \mathrm{Cl})$ & & 540 & & 546 & $100 \%$ & $0.83(0.57-1.20)$ & \\
\hline $\begin{array}{l}\text { Total events } \\
\text { Heterogeneity: Tau² }\end{array}$ & $\begin{array}{l}128 \\
0.03: \mathrm{Ch}\end{array}$ & $i^{2}=2$. & $\begin{array}{l}146 \\
5: d f=2\end{array}$ & $(P=$ & $\left.\right|^{2}=22 \%$ & & \\
\hline Test for overall effec & $Z=1.01$ & $(P=.3$ & & & & 0.01 & $\begin{array}{l}0.1 \\
\text { s HFNC }\end{array}$ \\
\hline
\end{tabular}

Fig. 2. Invasive mechanical ventilation: high-flow nasal cannula (HFNC) versus noninvasive ventilation (NIV).

\begin{tabular}{|c|c|c|c|c|c|c|c|c|}
\hline \multirow{2}{*}{$\begin{array}{l}\text { Study or Subgroup } \\
\text { Corley et } \mathrm{al}^{16}\end{array}$} & \multicolumn{2}{|c|}{ HFNC } & \multicolumn{2}{|c|}{ Standard $\mathrm{O}_{2}$} & \multirow{2}{*}{ Weight } & \multirow{2}{*}{$\begin{array}{c}\text { Odds Ratio } \\
\text { M-H, Random, 95\% Cl } \\
0.30(0.01-7.49)\end{array}$} & \multicolumn{2}{|c|}{$\begin{array}{c}\text { Odds Ratio } \\
\text { M-H, Random, 95\% Cl }\end{array}$} \\
\hline & 0 & 81 & 1 & 74 & & & & \\
\hline Frat et al ${ }^{12}$ & 40 & 106 & 44 & 94 & $43.1 \%$ & $0.69(0.39-1.21)$ & - & \\
\hline Lemiale et $a^{19}$ & 4 & 52 & 2 & 48 & $14.9 \%$ & $1.92(0.33-10.97)$ & & \\
\hline Maggiore et $\mathrm{al}^{14}$ & 2 & 53 & 11 & 52 & $17.4 \%$ & $0.15(0.03-0.70)$ & & \\
\hline Parke et $\mathrm{al}^{17}$ & 3 & 29 & 8 & 27 & $19.2 \%$ & $0.27(0.06-1.17)$ & & \\
\hline Total $(95 \% \mathrm{Cl})$ & & 321 & & 295 & $100 \%$ & $0.49(0.22-1.08)$ & & \\
\hline Total events & 49 & & 66 & & & & & \\
\hline $\begin{array}{l}\text { Heterogeneity: Tau }{ }^{2} \\
\text { Test for overall effec }\end{array}$ & $\begin{array}{l}0.29 ; \mathrm{Cr} \\
\mathrm{Z}=1.77\end{array}$ & $\begin{array}{l}\mathrm{il}^{2}=6 . \\
(P=.\end{array}$ & $\begin{array}{l}7 ; \mathrm{df}= \\
\text { 8) }\end{array}$ & $P=$ & $1^{2}=37 \%$ & $0 . \mathbf{n}^{\mathrm{r}}$ & $\begin{array}{l}0.1 \\
\text { rs HFNC }\end{array}$ & $\begin{array}{rr}1 & 1 \\
\text { Favors St }\end{array}$ \\
\hline
\end{tabular}

Fig. 3. Invasive mechanical ventilation: high-flow nasal cannula (HFNC) versus standard $\mathrm{O}_{2}$ therapy.

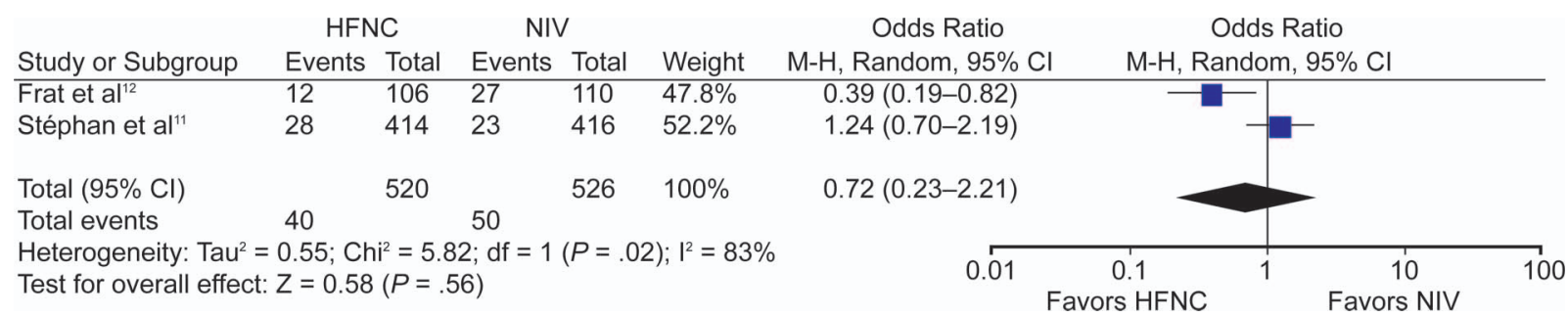

Fig. 4. ICU mortality: high-flow nasal cannula (HFNC) versus noninvasive ventilation (NIV).

$(101 \pm 34 \mathrm{~mm} \mathrm{Hg} \text { vs } 129 \pm 38 \mathrm{~mm} \mathrm{Hg}, P<.01)^{16}$ and in terms of $\mathrm{P}_{\mathrm{aO}_{2}} / \mathrm{F}_{\mathrm{IO}_{2}} 1 \mathrm{~h}$ and $6-12 \mathrm{~h}$ post-intervention in surgical subjects. ${ }^{11}$ HFNC was associated with an increased $\mathrm{P}_{\mathrm{aO}} / \mathrm{F}_{\mathrm{IO}}$ ratio compared with an air-entrainment mask in 2 studies: $101 \pm 34 \mathrm{~mm} \mathrm{Hg}$ versus
$85 \pm 21 \mathrm{~mm} \mathrm{Hg}(P<.001)^{16}(30 \mathrm{~min}$ post-intervention $)$ and at 24-48 $\mathrm{h}$ post-intervention but not in the first 24-h period in another study. ${ }^{17}$ In obese post-cardiac surgery subjects following extubation, there was no difference between HFNC and standard oxygen therapy in 


\section{HFNC in CRitically Ill Subjects With or at Risk for Respiratory Failure}

\begin{tabular}{|c|c|c|c|c|c|c|c|c|}
\hline \multirow[b]{2}{*}{ Study or Subgroup } & \multicolumn{2}{|c|}{ HFNC } & \multicolumn{3}{|c|}{ Standard $\mathrm{O}_{2}$} & \multirow{2}{*}{$\begin{array}{c}\text { Odds Ratio } \\
\mathrm{M}-\mathrm{H}, \text { Random, } 95 \% \mathrm{Cl}\end{array}$} & \multirow{2}{*}{$\begin{array}{c}\text { Odds Ratio } \\
\text { M-H, Random, } 95 \% \mathrm{Cl}\end{array}$} & \\
\hline & Events & Total & Events & Total & Weight & & & \\
\hline Frat et $\mathrm{al}^{12}$ & 12 & 106 & 18 & 94 & $69.2 \%$ & $0.54(0.24-1.19)$ & & \\
\hline Maggiore et $\mathrm{al}^{14}$ & 6 & 53 & 5 & 52 & $30.8 \%$ & $1.20(0.34-4.20)$ & & \\
\hline Total $(95 \% \mathrm{Cl})$ & & 159 & & 146 & $100 \%$ & $0.69(0.33-1.42)$ & & \\
\hline Total events & 18 & & 23 & & & & & \\
\hline $\begin{array}{l}\text { Heterogeneity: } \mathrm{Tau}^{2} \\
\text { Test for overall effec }\end{array}$ & $\begin{array}{l}0.03 ; \mathrm{Cr} \\
Z=1.01\end{array}$ & $\begin{array}{l}\mathrm{i}^{2}=1.1 \\
(P=.3\end{array}$ & $\begin{array}{l}\text { 2; } d f= \\
\text { 1) }\end{array}$ & $(P=$ & $\mathrm{d}^{2}=$ & 0.0 & $\begin{array}{c}0.1 \\
\text { avors HFNC }\end{array}$ & $\begin{array}{ll}10 \quad 100 \\
\text { Standard } \mathrm{O}_{2}\end{array}$ \\
\hline
\end{tabular}

Fig. 5. ICU mortality: high-flow nasal cannula (HFNC) versus standard $\mathrm{O}_{2}$ therapy.

$\mathrm{P}_{\mathrm{aO}} / \mathrm{F}_{\mathrm{IO}_{2}}$ in the first 24 h. ${ }^{18}$ There was no evidence of publication bias in the 4 meta-analyses performed, without asymmetry in the top or in the bottom of the funnel plot, based on visual inspection.

\section{Discussion}

This systematic review and meta-analysis suggested that there was no difference in mortality or the need for invasive mechanical ventilation when HFNC is compared with NIV; the same conclusions can be reached when compared with standard oxygen therapy. These outcomes were compared in a highly heterogeneous population, in clinical, ${ }^{12,15,19}$ surgical, ${ }^{11,17,18}$ and periprocedure subjects, ${ }^{9}$ in acute respiratory failure or in a postextubation context. ${ }^{17,18}$ It is important to highlight that the main exclusion criteria in most studies were COPD and hypercapnia, conditions in which NIV is a wellestablished indication that has an impact on mortality rate. ${ }^{21}$ In other settings, when NIV use is open to debate, as in postextubation patients, ${ }^{21}$ HFNC should be a useful alternative that has been associated in many studies with increased patient comfort and reductions in dyspnea scores. ${ }^{14,16,17}$ This outcome, however, due to heterogeneous measurement between studies and different forms of "patient comfort" characterization, an issue with several assessment tools without a validated approach in critically ill patients, ${ }^{22}$ limits our ability to reach a definitive conclusion about this point. Assessing dyspnea by a patient report instrument, such as the modified Borg scale, can be an important proposal for future studies to evaluate this outcome, and new studies will be necessary to determine whether this outcome will be an important factor in choosing an oxygen therapy interface, because mask intolerance and discomfort still represent a major cause of NIV failure. ${ }^{23}$

Another important study limitation is that different measurements were used for oxygenation improvement in the studies, which prohibits a definitive measurement of the magnitude of the intervention. This remains an open debate, despite apparent superior results associated with HFNC use when compared with standard oxygen therapy and inferior results when compared with NIV as presented in this paper. These results should be interpreted with great caution because quite different clinical scenarios existed when HFNC was tested; different times of administration of therapy and, consequently, different times for outcome evaluation were used. The analyzed studies included outcome measurements as early as $2 \mathrm{~h}$ and as late as 2 calendar days. ${ }^{12}$

Inspired gases in HFNC are warmed and humidified, improving comfort and possibly reducing airway inflammation, ${ }^{24}$ leading to improved drainage of respiratory secretions. ${ }^{17}$ Additionally, the high flows match the high spontaneous inspiratory flows generated by patients with dyspnea, reducing entrainment of room air and permitting delivery of more reliable $\mathrm{F}_{\mathrm{IO}_{2}}{ }^{25}$ A reduction in tachypnea also should occur by flushing out anatomical dead space in the upper airway by high oxygen flux. ${ }^{26}$

Despite several physiological advantages of HFNC, such as constant $\mathrm{F}_{\mathrm{IO}_{2}}$ during peak inspiratory flow, improvements in oxygenation, washout of the nasopharyngeal dead space, reducing the work of breathing, ${ }^{19}$ generation of flowdependent PEEP, and an increase in end-expiratory lung volume, ${ }^{27}$ its use is not free of limitations, such as those that have been established in postextubation postoperative cardiac surgery patients with body mass index $\geq 30 \mathrm{~kg} / \mathrm{m}^{2}$, in whom HFNC did not improve atelectasis, when a low level of PEEP (no more than 3-4 $\mathrm{cm} \mathrm{H}_{2} \mathrm{O}$ ) provided by HFNC should not be sufficient. ${ }^{2,18}$ It should be noted that prolonged HFNC use ( $\geq 48 \mathrm{~h}$ ) is associated with sequential failure and delayed intubation and may increase ICU mortality. ${ }^{28}$

Acute respiratory failure is not a unique physiopathologic model, and HFNC is not appropriate in all cases. In a patient with hypoxemia alone, oxygen therapy is often sufficient to correct the condition. In contrast, although HFNC may normalize oxygen saturation, it may not be sufficient to correct the underlying disturbance when there is a ventilation-to-perfusion ratio mismatch or in the context of alveolar hypoventilation, when a reduction in the work of breathing is necessary with PEEP and inspiratory pressure support.

New perspectives for HFNC trials are open, and more studies will be needed to determine whether the early ap- 


\section{HFNC in CRitically Ill Subjects With or at Risk for Respiratory Failure}

plication of HFNC avoids ICU admission in patients presenting to the emergency department with acute respiratory failure ${ }^{3}$ and in severe acute respiratory infection, situations in which HFNC therapy appears to be an effective modality for early treatment in patients who were unable to maintain adequate pulse oximetry with conventional oxygen therapy. ${ }^{29}$ In acute heart failure, important results in a pilot study ${ }^{30}$ identified a promising research agenda, especially concerning the degree of discomfort and intolerance associated with NIV that could be related to treatment failure.

\section{Conclusions}

In critical illness acute respiratory failure or in subjects at risk for it, HFNC did not demonstrate inferior results compared with conventional oxygen therapy or NIV in terms of ICU mortality and invasive mechanical ventilation rate. The data on oxygenation improvement suggest that HFNC could be superior to standard oxygen therapy but inferior to NIV, but with current knowledge, this is still an open question. Patient comfort and reduction in dyspnea scores will require further investigation because these are concerns in the consideration of HFNC as a promising therapy.

\section{REFERENCES}

1. Nishimura M. High-flow nasal cannula oxygen therapy in adults. J Intensive Care 2015;3(1):15.

2. Futier E, Jaber S. High-flow nasal cannula following extubation: is more oxygen flow useful after surgery? Intensive Care Med 2015; 41(7):1310-1313

3. Gotera C, Díaz Lobato S, Pinto T, Winck JC. Clinical evidence on high flow oxygen therapy and active humidification in adults. Rev Port Pneumol 2013;19(5):217-227.

4. Mayfield S, Jauncey-Cooke J, Hough JL, Schibler A, Gibbons K, Bogossian F. High-flow nasal cannula therapy for respiratory support in children. Cochrane Database Syst Rev 2014;(3):CD009850.

5. Dani C, Pratesi S, Migliori C, Bertini G. High flow nasal cannula therapy as respiratory support in the preterm infant. Pediatr Pulmonol 2009;44(7):629-634.

6. Sztrymf B, Messika J, Bertrand F, Hurel D, Leon R, Dreyfuss D, Ricard JD. Beneficial effects of humidified high flow nasal oxygen in critical care patients: a prospective pilot study. Intensive Care Med 2011;37(11):1780-1786.

7. Cuquemelle E, Pham T, Papon JF, Louis B, Danin PE, Brochard L. Heated and humidified high-flow oxygen therapy reduces discomfort during hypoxemic respiratory failure. Respir Care 2012;57(10):15711577.

8. Messika J, Ben Ahmed K, Gaudry S, Miguel-Montanes R, Rafat C, Sztrymf B, et al. Use of high-flow nasal cannula oxygen therapy in subjects with ARDS: a 1-year observational study. Respir Care 2015; 60(2):162-169.

9. Simon M, Braune S, Frings D, Wiontzek AK, Klose H, Kluge S. High-flow nasal cannula oxygen versus non-invasive ventilation in patients with acute hypoxaemic respiratory failure undergoing flexible bronchoscopy: a prospective randomised trial. Crit Care 2014; 18(6):712.
10. Miguel-Montanes R, Hajage D, Messika J, Bertrand F, Gaudry S, Rafat $\mathrm{C}$, et al. Use of high-flow nasal cannula oxygen therapy to prevent desaturation during tracheal intubation of intensive care patients with mild-to-moderate hypoxemia. Crit Care Med 2015;43(3): 574-583.

11. Stéphan F, Barrucand B, Petit P, Rézaiguia-Delclaux S, Médard A, Delannoy B, et al. High-flow nasal oxygen vs noninvasive positive airway pressure in hypoxemic patients after cardiothoracic surgery. JAMA 2015;313(23):2331-2339.

12. Frat JP, Thille AW, Mercat A, Girault C, Ragot S, Perbet S, et al High-flow oxygen through nasal cannula in acute hypoxemic respiratory failure for the fLORALI Study Group and the REVA Network. N Engl J Med 2015;372(23):2185-2196.

13. Liberati A, Altman DG, Tetzlaff J, Mulrow C, Gøtzsche PC, Ioannidis JPA, et al. The PRISMA statement for reporting systematic reviews and meta-analyses of studies that evaluate health care interventions: explanation and elaboration. J Clin Epidemiol 2009;62(10): e1-e34.

14. Tiruvoipati R, Lewis D, Haji K, Botha J. High-flow nasal oxygen vs high-flow face mask: a randomized crossover trial in extubated patients. J Crit Care 2010;25(3):463-468.

15. Parke RL, McGuinness SP, Eccleston ML. A preliminary randomized controlled trial to assess effectiveness of nasal high-flow oxygen in intensive care patients. Respir Care 2011;56(3):265-270.

16. Schwabbauer N, Berg B, Blumenstock G, Haap M, Hetzel J, Riessen R. Nasal high-flow oxygen therapy in patients with hypoxic respiratory failure: effect on functional and subjective respiratory parameters compared to conventional oxygen therapy and non-invasive ventilation (NIV). BMC Anesthesiol. 2014;14:66.

17. Maggiore SM, Idone FA, Vaschetto R, Festa R, Cataldo A, Antonicelli $\mathrm{F}$, et al. Nasal high-flow vs Venturi mask oxygen therapy after extubation: effects on oxygenation, comfort and clinical outcome. Am J Respir Crit Care Med 2014;190(3):282-288.

18. Corley A, Bull T, Spooner AJ, Barnett AG, Fraser JF. Direct extubation onto high-flow nasal cannulae post-cardiac surgery versus standard treatment in patients with a $\mathrm{BMI} \geq 30$ : a randomised controlled trial. Intensive Care Med 2015;41(5):887-894.

19. Lemiale V, Mokart D, Mayaux J, Lambert J, Rabbat A, Demoule A, et al. The effects of a 2-h trial of high-flow oxygen by nasal cannula versus Venturi mask in immunocompromised patients with hypoxemic acute respiratory failure: a multicenter randomized trial. Crit Care 2015;19:380.

20. Parke R, McGuinness S, Eccleston M. Nasal high-flow therapy delivers low level positive airway pressure. Br J Anaesth 2009;103(6): 886-890.

21. Cabrini L, Landoni G, Oriani A, Plumari VP, Nobile L, Greco M, et al. Noninvasive ventilation and survival in acute care settings. Crit Care Med 2015;43(4):880-888.

22. Chanques G, Nelson J, Puntillo K. Five patient symptoms that you should evaluate every day. Intensive Care Med 2015;41(7):13471350

23. Huang Z, Chen YS, Yang ZL, Liu JY. Dexmedetomidine versus midazolam for the sedation of patients with non-invasive ventilation failure. Intern Med 2012;51(17):2299-2305

24. Roca O, Riera J, Torres F, Masclans JR. High-flow oxygen therapy in acute respiratory failure. Respir Care 2010;55(4):408-413.

25. Spoletini G, Alotaibi M, Blasi F, Hill NS. Heated humidified highflow nasal oxygen in adults: mechanisms of action and clinical implications. Chest 2015;148(1):253-261.

26. Kumar H, Spence CJT, Tawhai MH. Modeling the pharyngeal pressure during adult nasal high flow therapy. Respir Physiol Neurobiol 2015;219:51-57. 


\section{HFNC in CRitically Ill Subjects With or at Risk for Respiratory Failure}

27. Corley A, Caruana LR, Barnett AG, Tronstad O, Fraser JF. Oxygen delivery through high-flow nasal cannulae increase end-expiratory lung volume and reduce respiratory rate in post-cardiac surgical patients. Br J Anaesth 2011;107(6):998-1004.

28. Kang BJ, Koh Y, Lim CM, Huh JW, Baek S, Han M, et al. Failure of high-flow nasal cannula therapy may delay intubation and increase mortality. Intensive Care Med 2015;41(4):623-632.
29. Rello J, Pérez M, Roca O, Poulakou G, Souto J, Laborda C, et al. High-flow nasal therapy in adults with severe acute respiratory infection. J Crit Care 2012;27(5):434-439.

30. Roca O, Pérez-Terán P, Masclans JR, Pérez L, Galve E, Evangelista A, Rello J. Patients with New York Heart Association class III heart failure may benefit with high flow nasal cannula supportive therapy: high flow nasal cannula in heart failure. J Crit Care 2013;28(5):741-746. 